\title{
Access to Justice
}

\section{McMurtry Gardens of Justice}

\author{
John Atkin* MA (RCA) FRSS \\ Reader in Fine Art, Loughborough University,School of Art, English \& Drama
}

"Corresponding Author: John Atkin MA (RCA) FRSS, Reader in Fine Art, Loughborough University

\begin{abstract}
The Canadian Charter of Rights \& Freedoms might on first glance might seem like a dry watering hole for ideas aimed at stimulating a landmark sculpture for a major site in the heart of Toronto. However, like many major cities in the West, the cultural warp and weft of society is clearly visible within the street-scape and cultural fabric of Ontario society and the Charter recognizes the rights of these citizens.
\end{abstract}

\section{INTRODUCTION}

Migration, immigration, refugees, are an increasing dynamic of C21st society, so when I was presented with an opportunity to explore the tapestry of cultures which forms the central tenet of Canadian society I was keen to investigate the history \& culture of this vibrant City that might influence the development of a landmark artwork for McMurtry Gardens of Justice.

The Canadian Charter of Rights \& Freedoms contains an important precept, which is Access to Justice: - without which it would be impossible for a Canadian Citizen to access the Law Courts and assert their rights in a modern society. Within a multi-cultural society its vital for all people to be able to access the justice system and affirm their rights and freedoms and this became the underlying principle of my sculpture.

The process of making this sculpture was my first experience of Canada. The timeline for getting funding in place, as well as planning permission, (including the support of the Law Society of Upper Canada, who generously sponsored this project), took four years of careful negotiation before the finished design was endorsed by all parties involved in this project: a complex process in its own right. Four years was an unusually long time for a public art project to come to fruition, but it did allow me, via several visits to Canada, to absorb a range of influences that eventually percolated into the framework of my installation artwork.

The Ontario Lakes visually punctuate the landscape of this part of Canada and were visible at key stages throughout journeys I made from Toronto to the fabrication workshop at La Fontaine, perched on the edge of Lake Georgia. My numerous conversations with Mike Bilyk (Director, Lafontaine Iron Werks), as well as representatives of the Law Society of Upper Canada, enabled me to form a coherent perspective on Canadian post-industrial growth alongside the multi-cultural welcome-mat of its "tapestry of cultures", which has made Toronto the diverse bustling hub of creative and business energy it is today.

\section{Cultural Tapestry}

The "Access to Justice" project has taken four years of careful negotiation and numerous "visual concepts" before The Law Society of Upper Canada eventually selected my design for a prime location bridging Toronto's Nathan Phillips Square and University Avenue, via the pedestrianised promenade of McMurtry Gardens of Justice.

Philip Givens (November 7, 1892 - January 7, 1976) was the first Mayor of Toronto of Jewish faith, underpinning the cultural mosaic that characterises Canadian Society. He was the driving force behind the new City Hall designed by the celebrated Finnish architect Viljo Revell. Guided by Revells' passion for Henry Moore's sculptures, and Philip Givens dertmination to modernise the City, their 
collaboration eventuated in Moore's "Three Way Piece" (referred to as "The Archer") taking centre stage within the new Modernist civic square. The Archer heralded a significant change of attitude amongst the Canadian population during the 1960's Cultural Revolution in Toronto and laid down a design tenet for civic spaces to be coupled with public art, that has provided a lasting legacy to this present day.

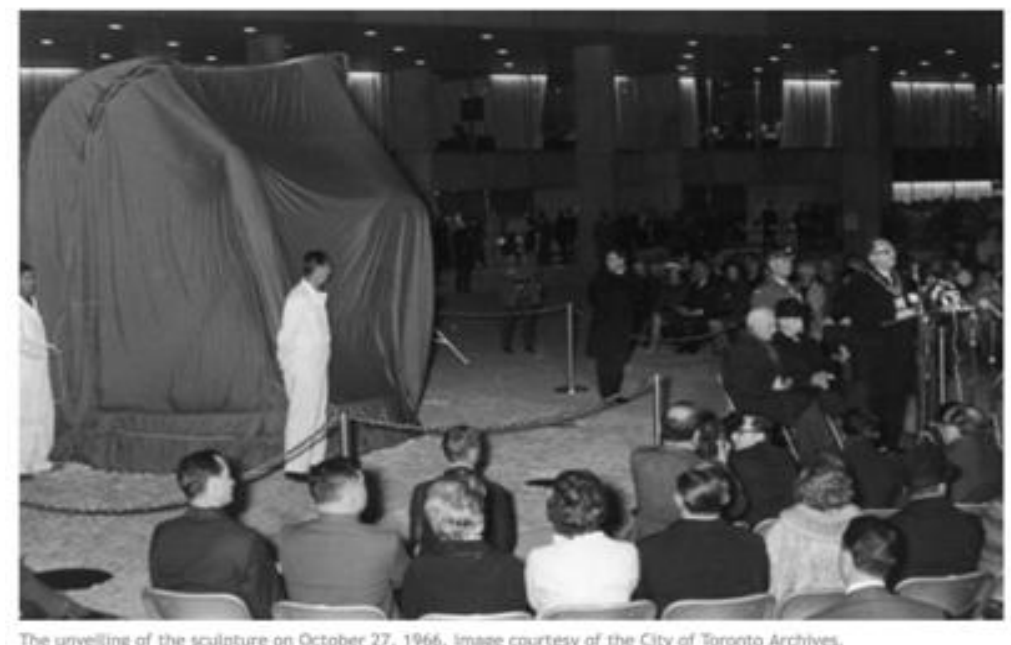

Canada is renowned as a tapestry of cultures, as opposed to the cultural melting pot of the United States. The distinction being that difference is celebrated in Canada and adds to the vitality of the country through the cosmopolitan diversity of migrants who have contributed to Canadian culture \& society.

Access to Justice forms a central tenet of the Canadian Carter of Rights and Freedoms and it was this principle, alongside ongoing worldwide contemporary politics relating to plight and migration that attracted me to the potential of this central principle of Canadian legislature.

The Access to Justice theme, based on the Canadian Charter of Rights and Freedoms, enables people from different backgrounds equality before the law. This fairness extends to all ethnic groups, gender and age groups.

The notion of removing barriers is central to the understanding of my artwork, and the proximity of the sculpture adjacent to the offices of the Law Courts of Upper Canada underpins this concept. Access to Justice is made from a combination of polished stainless steel, painted steel, and Corten steel. The polished stainless steel reflects the architectural surroundings as well as the colour and vibrancy of the busy everyday activity characterised by this space. The stainless steel is also a symbol for renewal and optimism, which was (and is) the driving force for so much migratory footfall to Canada.Stainless steel is a light-reflecting neutral material: its surfaces capture the reflections of all nationalities into the variousplanes of the artwork: thereby suggesting equalitybefore the Law and empowering all nationalities access to the rule ofLaw.

The Corten steel is a sealed rust coloured surface - symbolic ofthe past, as well as legacy-defining industries representing notions of human endeavour. Corten steel oxidizes to a bespoke hue of red depending on the atmospheric conditions it is located.The conjoining of the two metals creates a bridge between the old and the new. The use of the colour blue in this installation is also important as it create visual links to the Canadian Lakes, which are integral to Canadian identity.

Normally, the flat metalplanes of my sculpture would be read as a barrier or obstacle, except this landmark artwork has gateway apertures that allow the viewer to pass through a series of portals: a visualmetaphor for doorways to the Justice system. This physical and conceptual barrier is resonant of a series of rules that intersect at different points, with doorways that encourage access through the space. These apertures are disability aware to facilitate interaction for all users.

The sculpture is characterised by a series of gateways, at different heights, for all people. Crucially, from whatever angle you approach the sculpture from, the viewer will have a vista onto the Law Courts: a clear sightline from their own perspective, through the sculpture and onto the buildings that enshrine the justice system. 


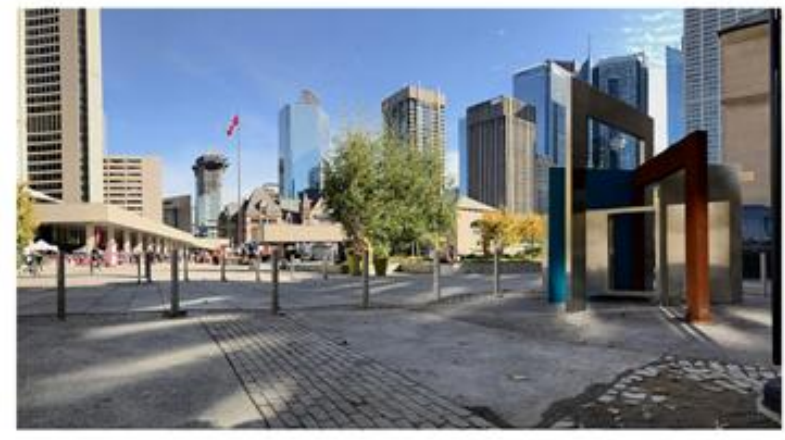

Access to Justice: 2017

Stainless steet: Corten Steel: Epoxy painted steel

$3.6 \times 2.7 \times 3.5 \mathrm{M}$

Fabricated at Lafontaine Iron Werks Ontario for McMurtry Gardens of Justice Toronto. John Atkin

As referred to earlier, my use of colour in this sculpture is important as it stimulates cognitive connectivity to the great expanses of water of Canada's Great Lakes, which creates a topographical three-dimensional contrast between land and water. Stainless steel is a light-reflecting neutral material: its surfaces capture the reflections of all nationalities into the forms of the artwork: thus suggesting equality before the Law and empowering all nationalities access to the Law.

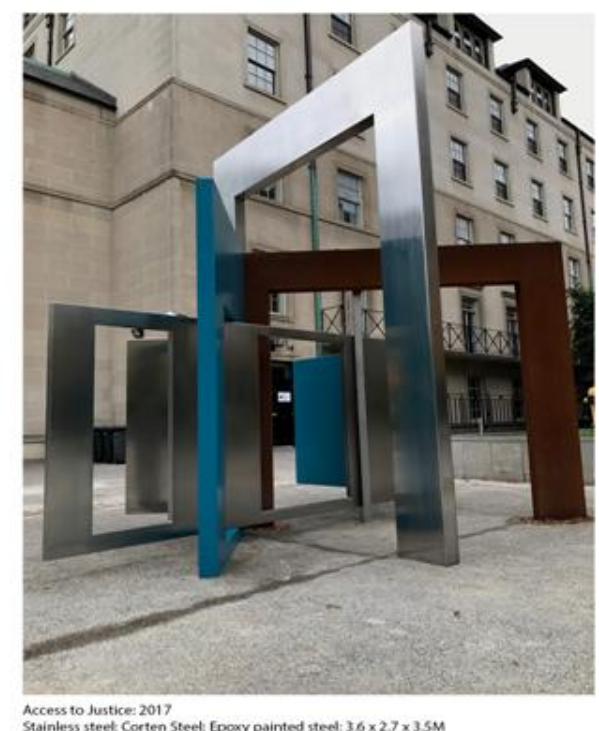

John Atkin

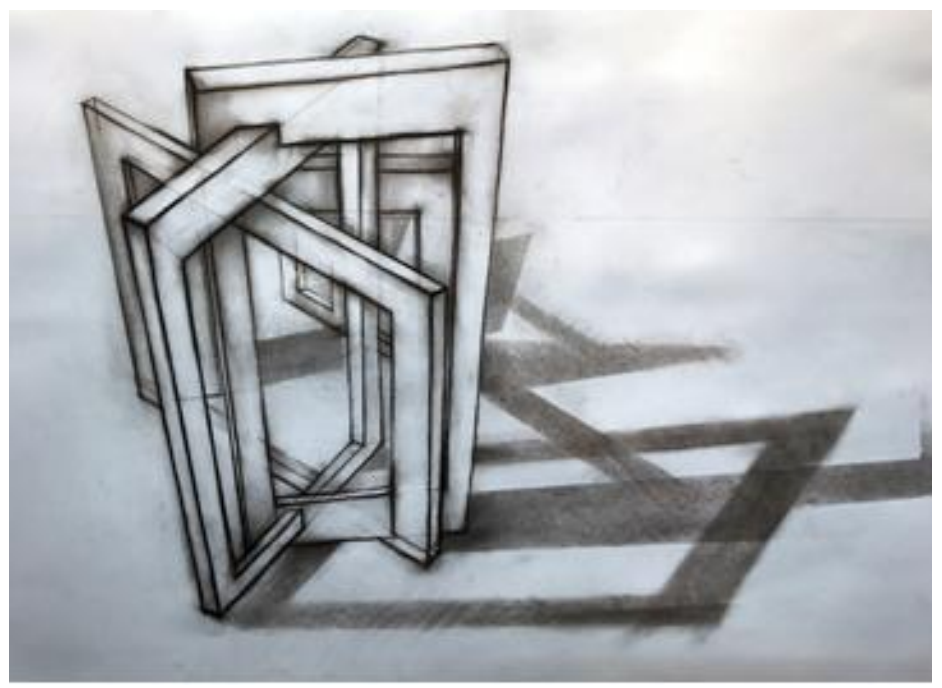

An early drawing (charcoal on paper) for Access to Justice. More works on paper can be located here 
When discussing issues of fairness and justice, it's appropriate to contextualize my sculpture with the legacy of Judge Roy McMurtry (Born May 31 ${ }^{\text {st }}$, 1932) to whom the public thoroughfare where "Access to Justice" is locatedis dedicated, and whose presence graced the inauguration of my sculpture. He held several high offices including Attorney General, High Commissioner to Canada to the UK, and latterly Chief Justice of Ontario. He was regarded as a great unifier who was able to find common ground between competing voices.He was also a race relations commissioner creating pro bono services for the poor and underprivileged, lobbying lawyers to support the system of justice for all. His work with the youth of Toronto brought about the feted program Ontario Justice Education Network, which educates those at risk of the justice system.

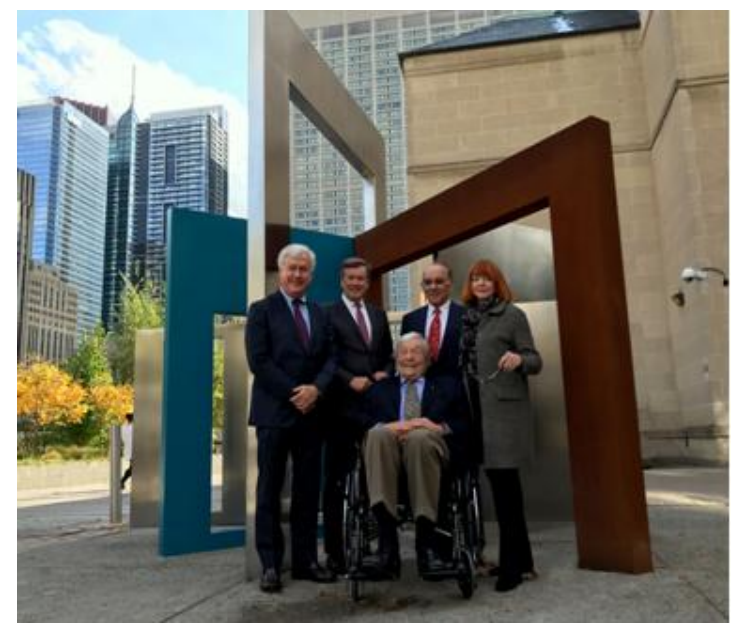

Judge Roy McMurtry (centre), flanked by (right to left) Gloria Epstein (supernumerary judge of the Court of Appeal for Ontario): Seymour Epstein (Chairman, Founder and Chief Executive Officer of Epstein Enterprises Inc): John Tory (Mayor of Toronto)

Furthermore, I'm indebted to Mike Bilykand his family for their generosity and hospitality during the course of making Access to Justice at Lafontaine Iron Werks Inc in Tiny, Ontario, and for allowing me to use one of his outbuildings as a studio to develop the models and drawings from which the sculpture was made

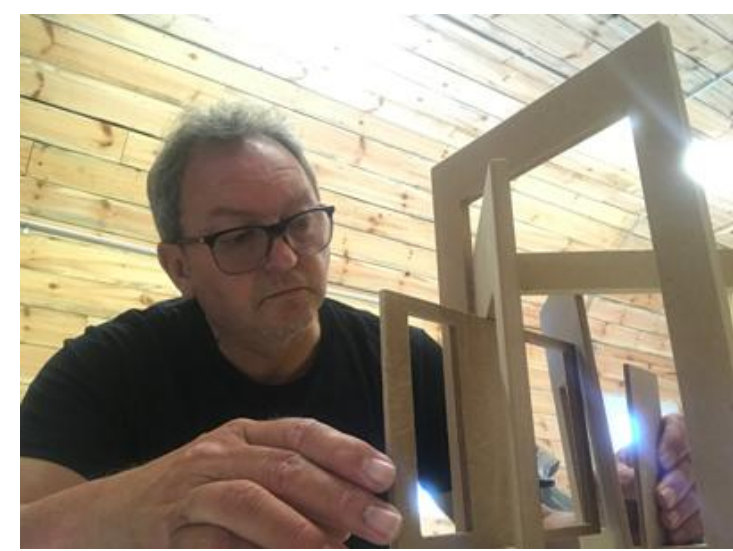

\section{CONCLUSION}

My sculpture "Access to Justice" reflects a vital tenet of the Canadian Charter of Rights \& Freedoms, through fabricated steel portals that frame vistas onto the Law Courts.

Whatever point you arrive at my sculpture, there is a view of the justice system which symbolically \& actually enshrines and protects Canadian Citizens. This is important for visitors, tourists and workers, as well as the continuous assembly of school children who visit McMurtry Gardens of Justice to enhance their understanding of their justice system.

My sculpture operates on several layers of meaning, that the sculpture reveals itself via multiple visits, possibly over weeks, but hopefully years.

A visitor will note that my sculpture is conspicuous because of its colour within the promenade space of McMurtry Gardens of Justice. As well as the colour blue referencing the Great Lakes, it also 
suggests seaborne maritime routes that generations of migrants will have used to find their way to Canada.

Canadian Society in the C19th moved from agriculture to manufacturing, hence my use of corten steel reflecting the importance of industry in building society and developing the economy.

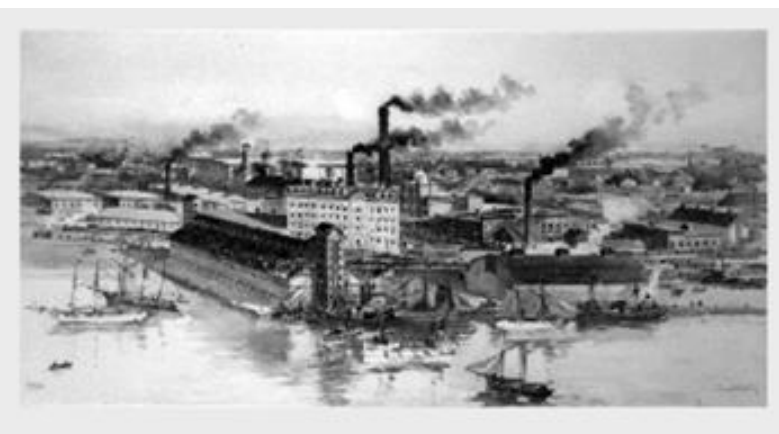

Toronto, Historical

Toronto, colour lithograph. Looking northeast at foot of Parliament. At the left, Gooderham \& Worts and other industries through which the city prospered (courtesy Baldwin Room, Metropolitan Toronto Library).

The trio of materials for my sculpture is completed by stainless steel. Canada is historically a major producer of nickel ore through its mining industry, and nickel ore is a key component of stainless steel. The polished surfaces of the stainless steel in Access to Justice reflect the architectural surroundings of Downtown Toronto as well as absorb the colour of the day, capturing the environment and reflecting if back onto the gaze of visitors to McMurtry Gardens of Justice.

Close to my sculpture, opposite City Hall is "The Archer", by Henry Moore. A sculpture that is a historical benchmark for Canadian visual culture opening the door for sculpture to be accessed beyond the boundaries of gallery walls. Access to "culture" is important for those who still feel excluded from the rarefied atmosphere of commercial galleries and museums.

More details about the installation of Access to Justice can be located here

\section{REFERENCES}

[1] The City of Toronto Archives (picture of "The unveiling of the sculpture on October 27, 1966)

[2] The Canadian Charter of Rights \& Freedoms

[3] All other photos courtesy of ArtAtk Ltd

\section{AUTHOR's BIOGRAPHY}

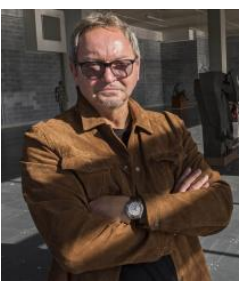

John Atkin MA (RCA) FRSS, Reader in Fine Art, Loughborough University, School of Art, English \& Drama

Citation: John Atkin, "The McMurtry Gardens of Justice”. International Journal of History and Cultural Studies (IJHCS). vol 4, no. 3, 2018, pp. 14-18. doi:DOI: http://dx.doi.org/ 10.20431/2454-7654.0403003.

Copyright: (C) 2018 Authors. This is an open-access article distributed under the terms of the Creative Commons Attribution License, which permits unrestricted use, distribution, and reproduction in any medium, provided the original author and source are credited. 